\title{
Power Distribution System Fault Alarm System Design and Implementation
}

\author{
Hongyong $\mathrm{Yu}$ \\ Electrical Engineering Department \\ Shandong Polytechnic \\ Jinan, China \\ E-mail: yu_hong_yong@163.com
}

\begin{abstract}
In order to control the fault state of the distribution network, a power distribution network fault risk early warning system is developed. This system divides the distribution network fault into three levels failures, equipment level failure, feeder level failure, and system level failure. By calculating the risk value, it sends an early warning message to a distribution operator when the risk value exceeds the limit value. It gets real-time operational data from distribution automation system via information bus, and gets equipment parameters from production management system via database. It uses equipment importance and equipment failure probability to calculate the equipment failure risk value. And then, it calculates the risk value for feeder level and system level. When the risk value exceeds a predetermined threshold, it starts alarm processing automatically and send warning message to the distribution operator. The results of application of the electric power company show that the system can detect faults in time and improve the reliability of power supply.
\end{abstract}

Keywords-power distribution fault; risk analysis; risk alarm; equipment failure; equipment importance; equipment failure probability

\section{INTRODUCTION}

Electric power distribution network is the key to the custom in the power system, but also the key to improve the quality of power supply. According to the statistics [1$3]$, more than $80 \%$ power supply failure interruptions are caused by the distribution network. So, it is important to build a system to monitor the running state of the distribution network and calculate distribution network fault risk value for early warning. And this will reduce the power failure time and improve the power supply quality of the customers.

Some experts have carried out extensive research on the assessment of the failure risk of distribution network[48]. Reference[4-5] proposes the time-varying component outage model with limited statistical failure data. The benefit of risk-based security-constrained optimal power flow model lies in its ability to improve the economic performance of a power system [6]. The equipment failure rate and the equipment failure outage impact degree is also be considered [7]. Pharos measurement unit (PMU) is used for online voltage security assessment [8-10]. Reference [11-12] propose a method of power system outage risk assessment based on the OPA model.

Due to the complexity of the distribution network and its running state, there is no instance for real-time on-line calculation and early warning. So, this paper presents a method for calculating the failure risk on-line using equipment importance and equipment failure probability. And this method is achieved by software based on distribution supervisory control and data acquisition (SCADA) system.

\section{STRUCTURE OF FAILURE RISK WARNING SYSTEM}

\section{A. Distribution Fault Objects}

A distribution network is a network that is distributed and composed by many feeders as shown in Fig.1. A feeder (such as Feeder 1) spreads electric power from a source to a number of load points. Two (Feeder 2 and Feeder 3) or more feeder often form an open loop network. Each feeder is similar to the radial feeder but they are able to support each other. For any cable fault, the customers downstream of the fault can be recommended to supply by switching the network around. The distribution network consists of a plurality of feeders which are joined in the substation bus and each feeder is composed of a large number of power equipment.

So, distribution network failure risk has three aspects: equipment failure risk, feeder failure risk, and system level failure risk. Equipment risk assessment objects include overhead power lines, cables, bar equipment, pole transformers and so on. The feeder is consisting of branch, distribution transform, switch, load. The system is composed of the feeder network. Equipment failure risk is the danger of power failure caused by different equipment on the feeder. It is the foundation of the evaluation of feeder level failure risk. And the feeder level failure risk is the foundation of the evaluation of system level failure risk. 


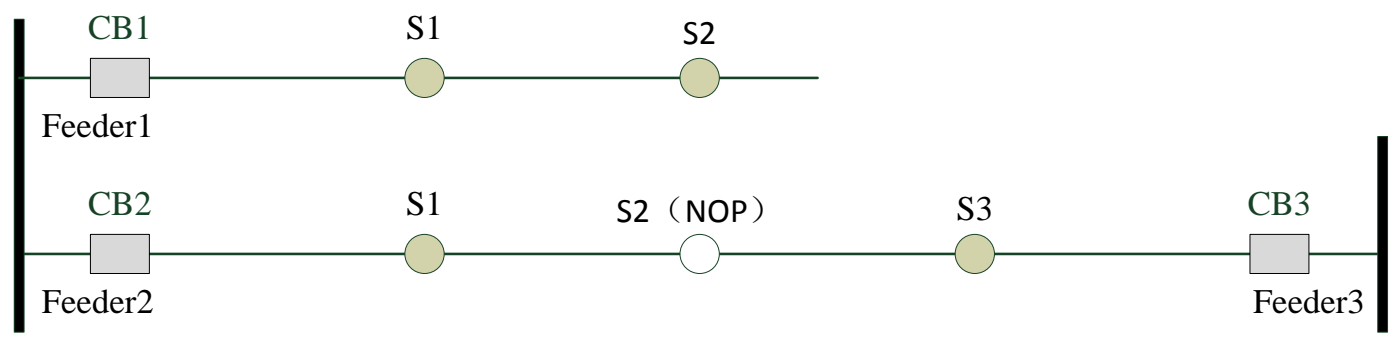

Figure 1. Distribution network

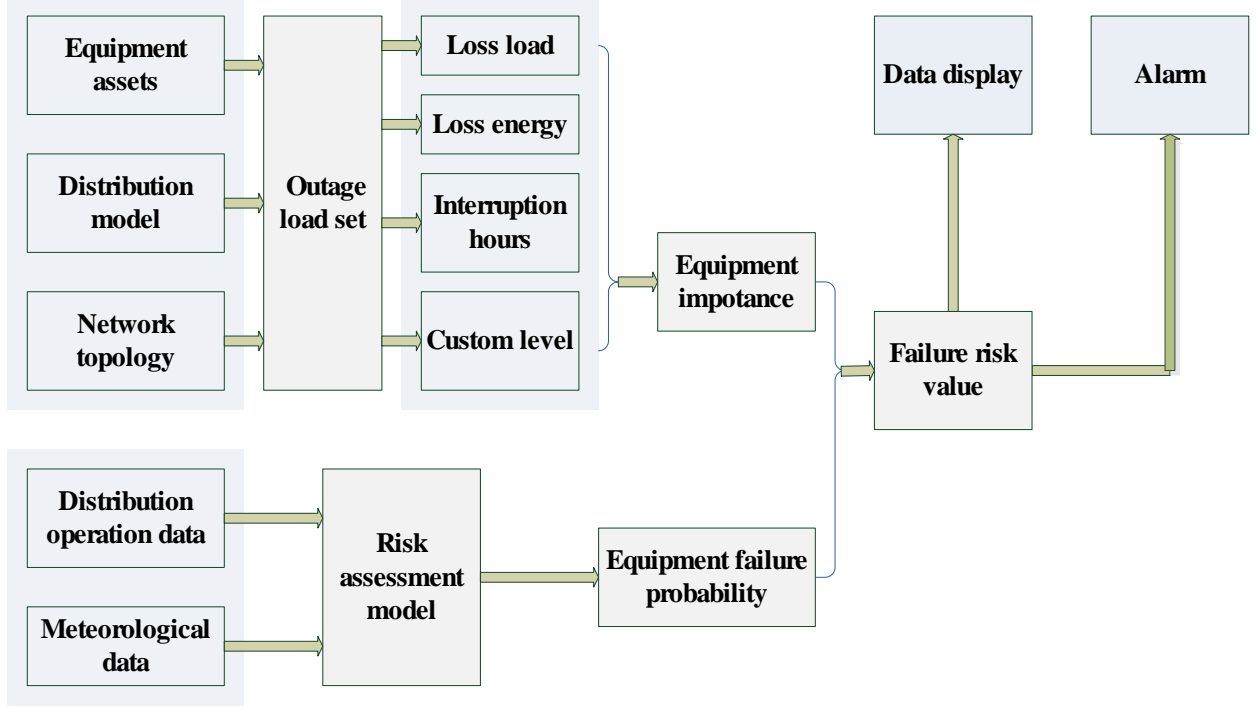

Figure 2. Software structure.

\section{B. Warning System Structure.}

The software structure of failure risk warning system for the distribution network is shown in Fig.2. The equipment failure risk is composed of two dimensions, the importance of equipment and equipment failure probability. The importance of the equipment is expressed by the consequence of the power failure caused by the equipment failure, and more serious the failure of equipment failure in the equipment is more important. The equipment failure probability indicates the probability of equipment failure, the greater the probability of the device is more prone to failure. The feeder level fault risk is calculated by the risk of failure of all the equipment on the feeder. The system failure risk is the risk of all devices in the system.

The risk value of the fault can be displayed for the user with a visual way, timely detection, clear the fault. After the failure risk value exceeds a certain threshold, the early warning program start, to reduce the probability of failure and the possibility of failure. So, it can improve power supply reliability.

\section{CALCULATION OF THE RISK VALUE}

\section{A. Equipment Level Fault Risk Value.}

First, calculate the importance of the equipment. After the failure of the distribution network feeder equipment, it is often using the fuse, circuit breaker and load switch to isolate the fault segments, and then close the break of substation, linked switch to supply the non fault segment. For different equipment in the distribution network, the consequences of the failure are not the same, some of the impact are big, and some are small. The degree of failure of the equipment in the distribution network, that is, the importance of the equipment. The failure of the equipment in the distribution network is the significant degree of the equipment. So, the following equipment important indicators which are of importance are used: loss of load (LL), loss of power energy (LE) and customer failure interruption hours $(\mathrm{CFIH})$, custom level (CL), as shown in Fig.1.

And then, calculate the failure probability of the equipment. The failure of equipment is the result internal factors and external factors. The internal factors mainly include: over load, equipment defects, potential fault, equipment using life. The external factors mainly include: high winds, heavy rain, lightning and other weather factors. It also includes construction damage and so on. So, the relationship between the risk source state and the probability of the occurrence of equipment is established. The status of the risk source of the equipment can be expressed by the service life of the equipment and the failure rate of the equipment itself. Equipment over load risk source is the state for the overload level. Heavy rain, lightning, and the construction risk source of the state is 0 or 1,1 is existing, 0 is not existing.

Equipment failure risk value is the product of equipment failure probability and importance of equipment. 
Equipment important value is 0 to 1 , and the equipment failure probability is 0 to 1 . Make an example, the importance of equipment is 0.6 , at a certain period of time, the failure probability is 0.025 , then the equipment failure risk value is $0.6 * 0.025=0.015$.

\section{B. Feeder Level Fault Risk Value.}

The feeder level fault risk is the risk of equipment failure on the feeder, and there is a risk value of the main equipment in the feeder. The mean value, maximum value and secondary value of the equipment risk in the feeder are reflected by the index of the feeder level risk. Considering the distribution network risk of multiple dimensions and complexity characteristics, single index by the influence of random error will be accordingly larger, in order to reduce the adverse effects caused by random error, establish the comprehensive index of feeder risk assessment.

\section{System Level Fault Risk Value.}

The feeder level fault risk is the risk of equipment failure on the feeder, and there is a risk value of the main equipment in the feeder. The distribution network is composed of a plurality of feeders, and the system level fault risk is derived from the feeder level fault risk. As the earthling different mode has different influence on the reliability of the distribution network, it is needed to neutral factors to consider in the distribution system failure risk value, so the neutral point connection mode is taken as an indicator.

\section{ON-LINE WARNING METHOD}

Distribution network fault on-line early-warning is built on the computation of the value at risk of fault. If the risk value exceeds a preset threshold, it will be alarm. According to the fault monitoring of the object, it can be split into 3 types, which are equipment level warning, feeder level warning and system level warning.

\section{A. Equipment Level Warning.}

According to the actual situation of distribution network operation, set a threshold for equipment failure risk value. When equipment failure risk value exceeds the threshold, the system uses coloring warning, flashing warning. Based on relevant database operations, sorting the equipment failure risk value, query the source of risk to the system. So, it is useful to the distribution network operation and maintenance personnel.

\section{B. Feeder Level Warning.}

By calculating the comprehensive risk value of each feeder, the main focus of the feeder is to determine the most important feeder. And then the actual conditions of the equipment risk on the feeder are observed, and the risk of critical feeders and their equipment, and the sensitivity of the feeder on the feeder is studied. Depending on the situation of the distribution network, set a reasonable threshold value of risk for feeder. When the feeder failure risk value exceeds the threshold, the system uses coloring warning, flashing warning. And the operator can query the warning feeder and the equipment of the feeder.

\section{System Level Warning.}

According to the situation of the operation of the distribution network, the distribution network fault system, set a threshold value for risk value. When the system failure value exceeds the threshold, the system sends out a warning message to the distribution operator.

\section{WARNING SYSTEM IMPLEMENTATION}

\section{A. Basis Function.}

The basic function of fault risk early warning system for distribution network:

(1) Importance evaluation of distribution network equipment;

(2) Identification the risk sources of distribution network equipment;

(3) Evaluate the fault probability of equipment based on the risk source state;

(4) Calculate equipment failure risk value, feeder failure risk value and the system failure risk, and sort to the risk value;

(5) When the risk value exceeds the threshold, send out warning message by flashing;

(6) Give the operator suggestion of the distribution network weak, and the risk source can be viewed, and provided for the system operation and maintenance personnel.

\section{B. System Structure.}

The software realization of the fault risk early warning system includes 2 parts, the fault risk assessment and the data interface module, and the system architecture is shown in Fig.3.

In Fig.3, with the real time operation data transmission time requirements, it is needed to use special interface to get the real time data from the SCADA system. And other data transmission time with no high requirements, such as distribution network topology, equipment status, historical data and other real-time requirements, can use the International Electrotechnical Commission (IEC) common information model (CIM) to obtain data in the database.

\section{Visualization and Human Computer Interaction.}

To express the risk information more intuitive and effective, the system provides a graphical risk visualization method and realizes the function of risk information visualization based on the visualization of statistical charts. Graphics display single line diagram and geographical map highlighting and coloring, flashing over warning threshold equipment directly show what equipment exceeds the warning threshold, and can be inquiry of the risks associated with data. Chart method for all distribution network object, all failure risk information comprehensive query and expression, is a kind of effective auxiliary visualization method, including distribution network the failure risk, simulation state failure risk and fault history curve risk related to a variety of form, disk table, table, chart and curve (as Fig.4). 


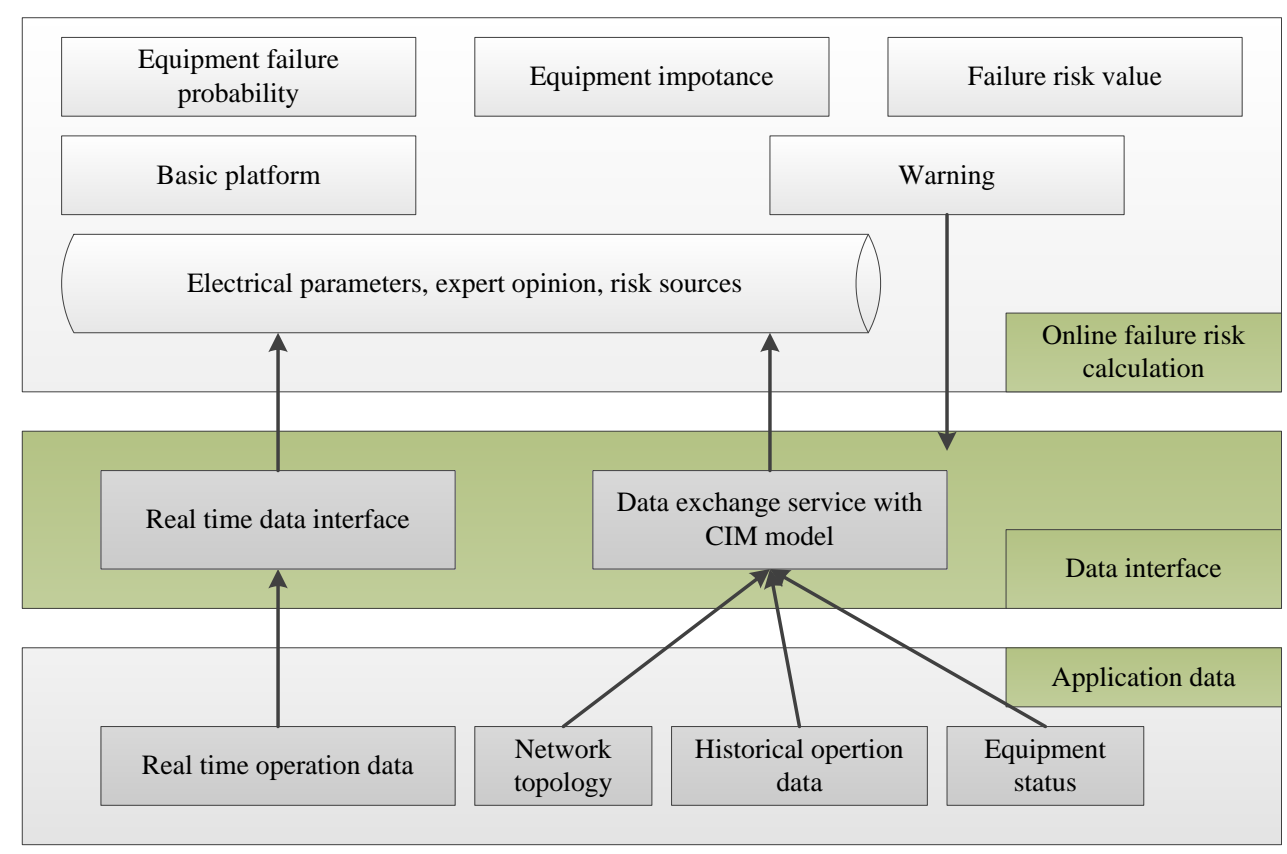

Figure 3. Risk warning system structure

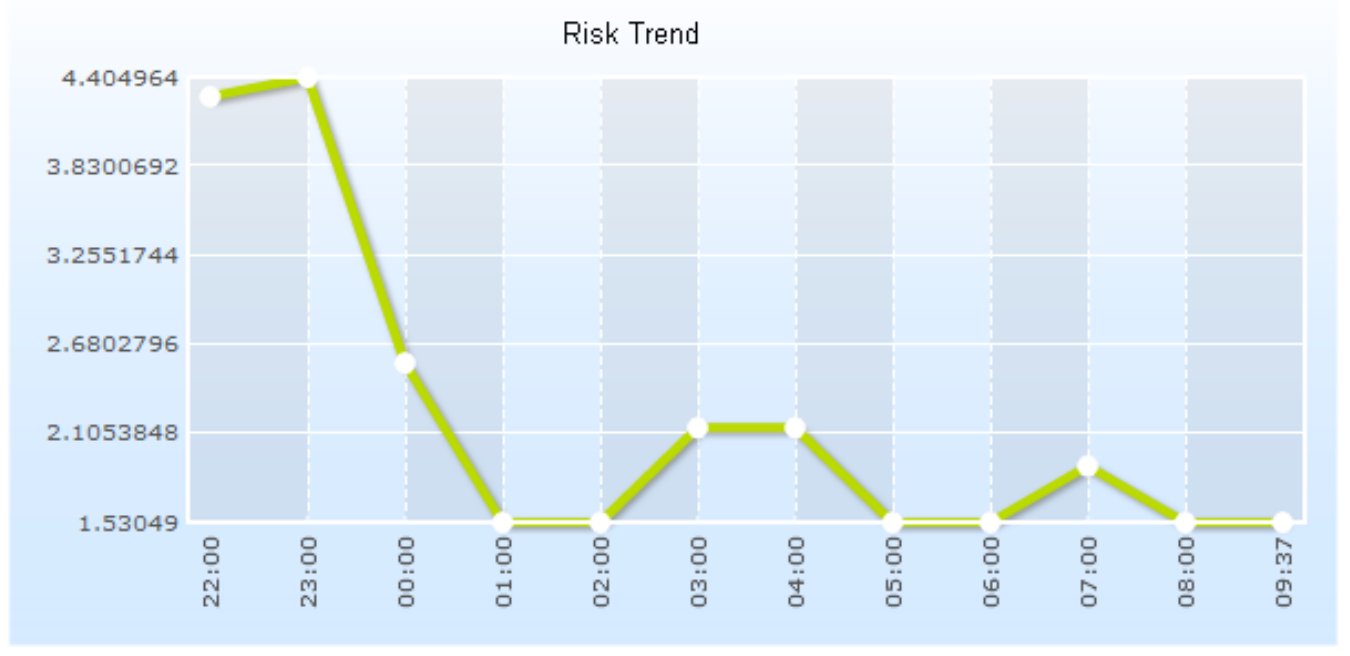

Figure 4. Equipment risk charts

Distribution system fault risk early warning system has developed since July 2013. And it is deployed in an eastern coastal city. An equipment risk value from 19:00 to 22:00 of July $18^{\text {th }}, 2013$ is shown in Fig.4, from which,, it can be observed that during 22:00 3:00, the risk value of the equipment is higher than normal time due to current. And from 15:00 to 16:00, because of heavy rainfall, the equipment risk value is higher.

\section{CONCLUSIONS}

In this paper, equipment importance and failure probability are used to calculate the risk value of the equipment. And then the risk value of the feeder and system is also calculated. When the risk value exceeds a threshold, the system sends out warning message. On the basis of this, the distribution network fault risk warning system is developed, and the real-time calculation of the risk value and the online early warning is realized. The results of the system show that the equipment is maintained in time and the maintenance of the equipment is improved, which can reduce the number of maintenance, and improve the reliability of power supply.

\section{REFERENCES}

[1] HU Xiaozheng,WANG Peng.Current Situation Analysis of Power Supply Reliability to Nationwide Urban Users in 2009[J].Distribution \& Utilization,2010,27(5):15-18,30.

[2] OFGEM. 2008/09 Electricity Distribution Quality of Service Report [R/OL]. http://www.ofgem.gov.uk/Networks/ ElecDist/ QualofServ/QoSIncent/Documents1/200809\%20Electricity\%20 Distribution\%20Quality\%20of\%20Service\%20report.doc.pdf.

[3] OFGEM. 2008/09 Electricity Distribution Quality of Service Data Tables [R/OL]. http://www.ofgem.gov.uk/Networks/ElecDist/ QualofServ/QoSIncent/Documents 1/200809\%20QOS\%20data\%20 tables.xls

[4] WU Wen-chuan,NING Liao-yi,ZHUANG Bo-ming,SUN Hongbin.Online operational risk assessment and decision making for 
power systems[J].Journal of Changsha University of Electric Power(Natural Science Edition),2009(2).

[5] WU Wen-chuan,NING Liao-yi,ZHUANG Bo-ming,SUN Hongbin.Online operational risk assessment and decision making for power systems[J].JOurnal of Electric Power Science And Technology,2009,24(2):28-34

[6] Wang Q, McCalley J D, Zheng T, et al. A computational strategy to solve preventive risk-based security-constrained OPF[J]. Power Systems, IEEE Transactions on, 2013, 28(2): 1666-1675.

[7] ZHAO Huiru,LI Nan,GUO Sen,LI Tianyou and ZHANG Gonglin.Real-time risk assessment on equipment failure outage of distribution network[J].Electric Power Automation Equipment,2014,34(11).

[8] GU Wei,DING Tao,YANG Ziqun,WAN Qiulan.Online Voltage Security Assessment Using Multiple Dynamic Decision Tree[J].Proceedings of the CSEE,2011,31(31).
[9] ZHANG Dao-nong,LIU Hao,BI Tian-shu,HU Yu-lan and ZHANG Xiao-li.Comparison of the PMU static and dynamic standards and evaluation methods between Chinese standards and IEEE[J].Power System Protection and Control,2013,V41(17):140-145.

[10] BI Tianshu,LIU Hao,WU Jingtao,YANG Qixun.On-line Assessment on Voltage Consistency and Frequency Consistency of PMU Measurement Under Steady State[J].Automation of Electric Power Systems, 2010,34(21):21-26..

[11] MEI Shengwei,HE Fei,ZHANG Xuemin,XIA Deming.An Improved OPA Model and the Evaluation of Blackout Risk[J].Automation of Electric Power Systems,2008,32(13):1-5.

[12] LU En,LU Xiaojun,LONG Fei,ZENG Kaiwen,WANG Ning,LIAO Shiwu and WEN Jinyu.Indexes and method of power system outage risk assessment[J].Electric Power Automation Equipment,2015,35(3). 